\title{
İzmir İli Nif Dağı Kazısı Buluntusu Altın Diademler
}

\author{
Gold Diadems from the Nif Mountain Excavations, İzmir
}

\begin{abstract}
Müjde PEKER ${ }^{*}$
Öz: İzmir'in doğusunda, Kemalpaşa, Torbalı ve Buca ilçelerinin ortak sınırları çevresinde konumlanan Nif (Olympos) Dağı'nda, ilk kez 2006 yılında Prof. Dr. Elif Tül TULUNAY başkanlığında başlanan arkeolojik kazılar, dağın doğu ve güneydoğu kesiminde sürdürülmektedir. İzmir İli Nif (Olympos) Dağı Kazısı çalışma alanlarından Karamattepe'de Arkaik Dönem yerleşimi yanı sıra Hellenistik Dönem'e tarihlendirilen bir nekropolis kazılmaktadır. Burada 2008 yılında açığa çıkarılan mezarda (KM 6) kremasyon kabı olarak kullanılmış pişmiş toprak amphora içinde 5 adet üçgen alınlıklı altın diadem bulunmuştur. Bu makalede, söz konusu diademler, buluntu yeri ve konteksti yanı sıra teknik ve üslup özellikleriyle değerlendirilmektedir.
\end{abstract}

Anahtar sözcükler: Nif Dağı, Hellenistik, Nekropolis, Kremasyon, Diadem

Abstract: The archaeological excavations directed by Prof. Dr. Elif Tül Tulunay since 2006 on Nif (Olympos) Mountain, to the east of İzmir, situated on the borders of Kemalpaşa, Buca and Torbalı counties, are being continued on the east and southeast region of the mountain. In Karamattepe, one of the excavation sites of the Nif (Olympos) Mountain Excavations, an Archaic settlement, in addition to a Hellenistic necropolis were excavated. Five pediment-shaped gold diadems were found inside a terracotta amphora which was used as cremation vessel for the grave (KM 6) unearthed in 2008. In this article these diadems are examined within their find spot context, in addition to recording their technical and stylistic features.

Keywords: Nif Mountain, Hellenistic, Necropolis, Cremation, Diadem

Nif (Olympos) Dağı, İzmir (Smyrna) Körfezi’nin doğusunda, Bornova, Buca, Kemalpaşa ve Torbalı ilçelerinin ortak sınırları çevresinde konumlanır. Kuzeyinde, Kemalpaşa (Nif-Kryos Çayı) Ovası ve Manisa (Sipylos) Dă̆g; doğusunda, Karabel Geçidi; güneyinde, Torbalı Ovası yer alır (Fig. 1). Arazi yapısı dolayısıyla su kaynaklarına, verimli topraklara ve madenlere sahiptir. Doğal dağ geçitleri sayesinde kıyı ve iç bölgelerle bağlantılıdır. Bu nedenlerle çok sayıda yerleşime ve kültür varlığına ev sahipliği yapmıştır. Nif (Olympos) Dağı'nda Prof. Dr. Elif Tül Tulunay başkanlığında gerçekleştirilen ön inceleme gezileri (1999-2001), yüzey araştırmaları (2004-2005) ve 2006 yılından beri dağın doğu ve güneydoğusundaki Karamattepe, Ballıcaoluk, Dağkızılca ve Başpınar mevkiilerinde devam eden kazılar, MÖ VIII. yüzyıl ile MS XIV. yüzyıl arasına tarihlendirilen yapı ve buluntuların varlı̆̆ını ortaya koymuştur. Karamattepe, başta keramik olmak üzere çeşitli buluntular ve yapı kalıntılarına göre Geometrik/Arkaik Dönem'de yerleşim ve Hellenistik Dönem'de nekropolis olarak kullanılmıştır. Yolların

\footnotetext{
* Yrd. Doç. Dr., İstanbul Üniversitesi, Edebiyat Fakültesi, Arkeoloji Bölümü, Klasik Arkeoloji Ana Bilim Dalı, İstanbul.mujde.peker@istanbul.edu.tr

Nif (Olympos) Dağı Araştırma ve Kazı Projesi, İstanbul Üniversitesi Rektörlüğü Bilimsel Araştırma Projeleri Komisyonu tarafindan desteklenmektedir.
} 
gözlenmesi için uygun konumdaki Ballıcaoluk, Hellenistik Dönem'de tahkimli bir kale işlevinde kullanılmıştır ve buradaki yerleşim hem Geometrik/Arkaik hem de Hellenistik Dönem'de Karamattepe'dekiyle yakın bağlantıya sahiptir. Dağkızılca'da çeşitli mezar tiplerinin (tümülüs, oda mezar, sandık mezar, pişmiş toprak lahit) bulunduğu nekropolis alanında çalışılmaktadır. Başpınar'da ise, Laskarisler Dönemi kilise kompleksi ortaya çıkarılmaktadır.

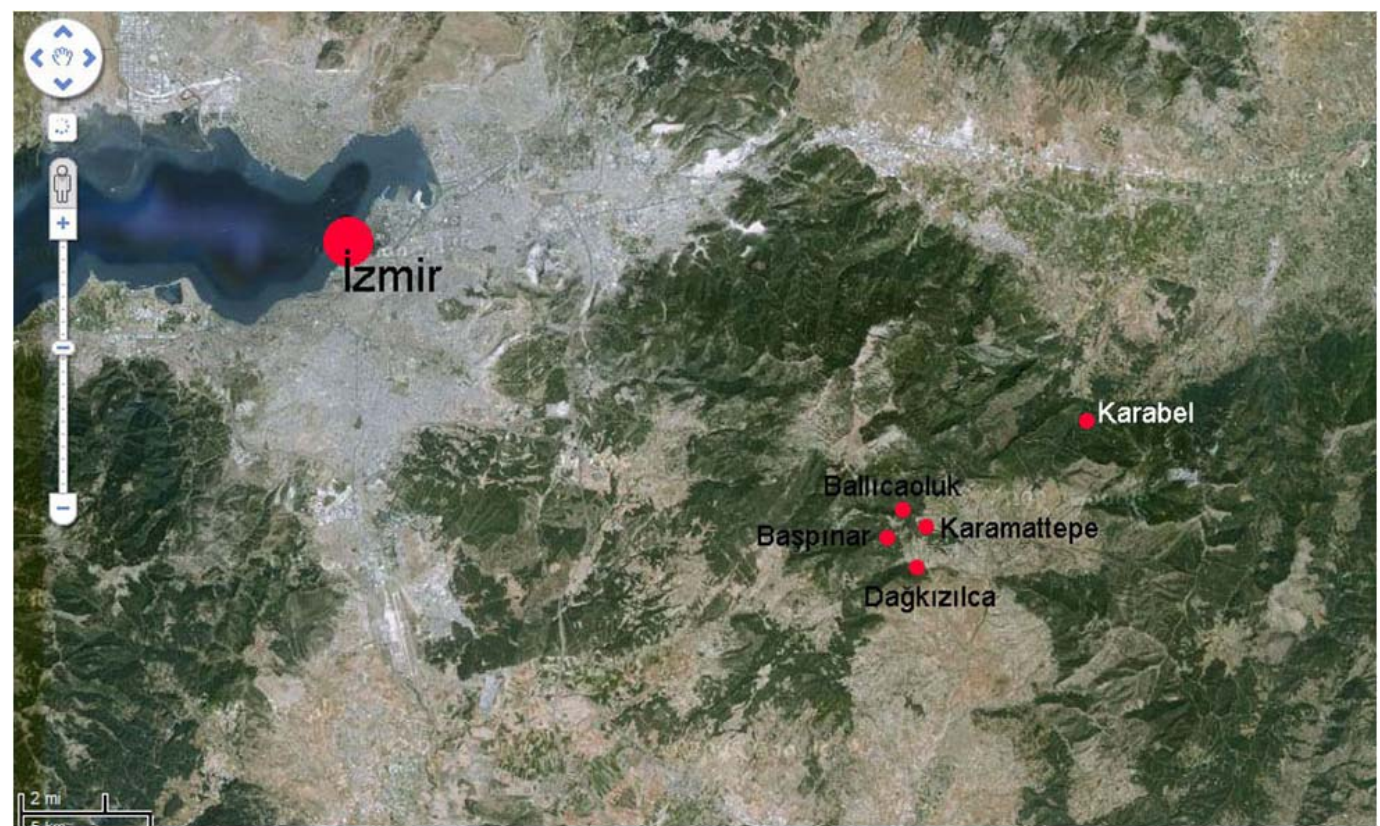

Fig. 1. Nif Dă̆ı Kazı alanları

\section{Karamattepe Mezar 6 (KM 6) Konteksti ve Tarihlendirilmesi}

Karamattepe'de 2008 yılında kazılan KM 6 kodlu amphora içi kremasyon mezarda, parçalar halinde 5 adet üçgen alınlıklı altın şerit diadem bulunmuştur. Mezarın üzeri dörtgen yassı bir taşla kapatılmış, güneyi ve batısı düzensiz taşlarla çevrelenmiştir (Fig. 2-3). Kremasyon kabı olarak kullanılan amphoranın yanında tek kulplu bir testi ve içe dönük kenarlı derin bir kase ele geçmiştir (Fig. 5). Amphoranın içinden diadem parçalarının yanı sıra 4 bireye ( 1 erkek, 1 kadın, 2 çocuk) ait yanmış kemik parçaları çıkarılmıştır. Hafif yayvan ve aşağı sarkık kenarlı ağız profiline sahip amphora, Erken Hellenistik Dönem formlarıla benzer özelliktedir (Tulunay 2010, 390-391, 404; Bilgin 2015, 37, lev. V.43).

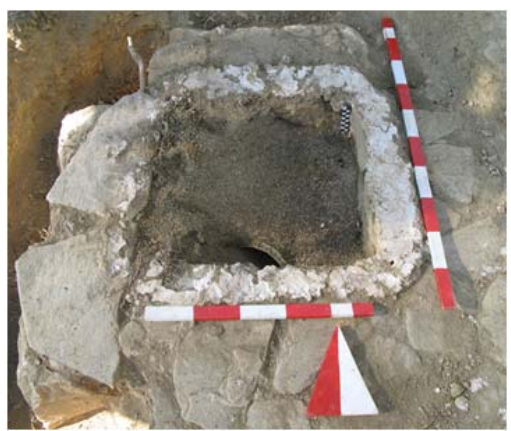

Fig. 3. KM 6'nın kazı aşaması

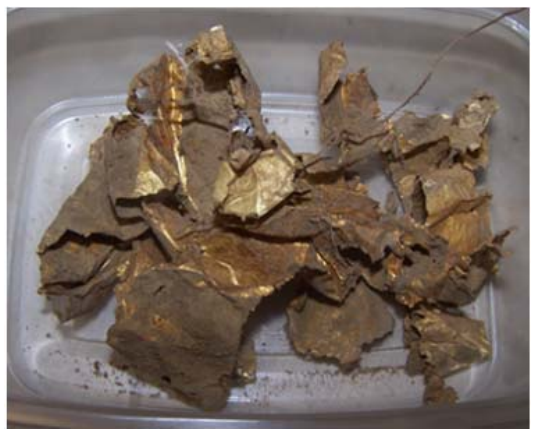

Fig. 4. Diademlerin onarım öncesi

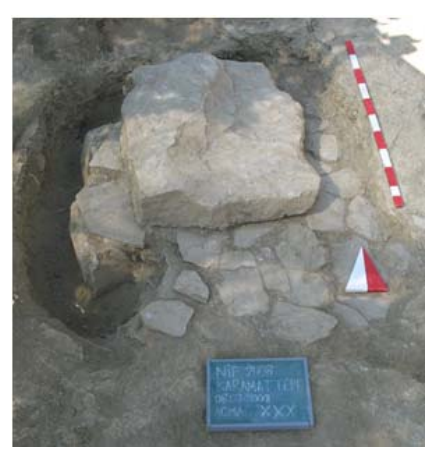

Fig. 2. KM 6'nın kazı öncesi

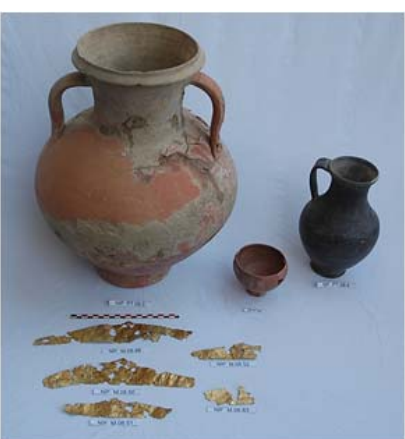

Fig. 5. KM 6 konteksti 
Diademlerin üçü (İzmir Müzesi Env. No. 851, 852, 853) tüme yakın (Fig. 6-8), ikisi (Fig. 9-10, İzmir Müzesi Env. No. 854 ve 855) yarım (Fig. 9-10) durumdadır. Kremasyon kabı olarak kullanılan amphoranın içinden buruşturulmuş ve çok parçalı halde çıkarılan (Fig. 4) diademler Nif Dağı Kazısı Onarım-Koruma Uzmanı Öğr. Üyesi Ceren Baykan'ın titiz çalışmasıyla temizlenerek uyan parçalar birleştirilmiştir.

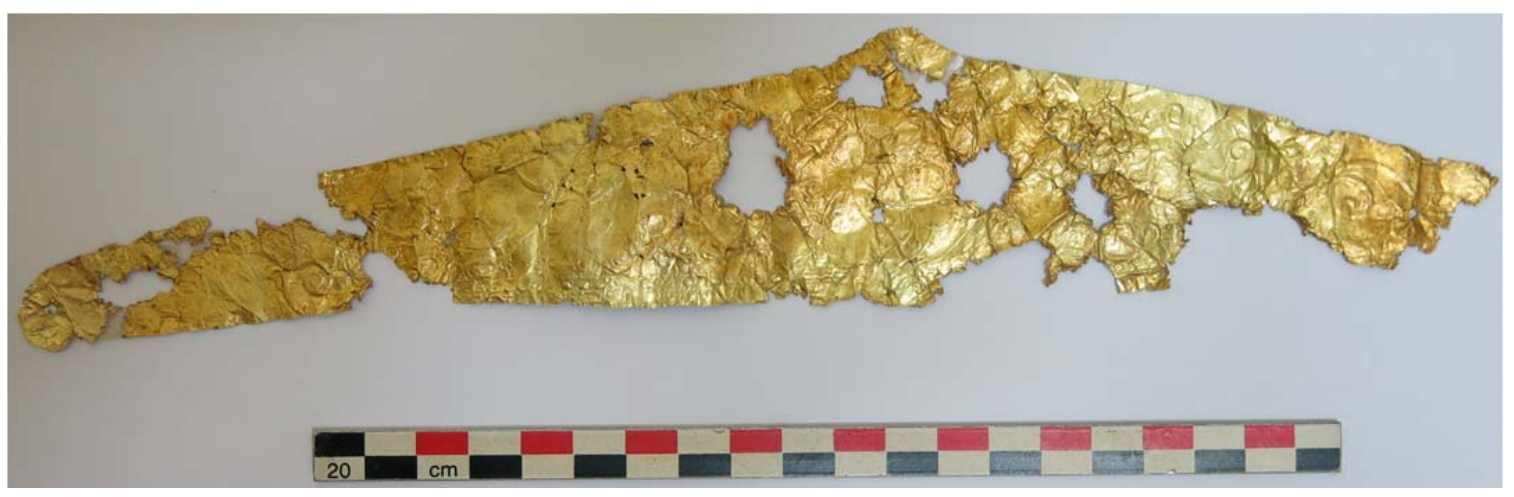

Fig. 6. Env. no. İzmir M. 851, Nif Dağı Kazısı M.08-49, yük. 5,4 cm, uz. 28,7 cm

KM 6, kontekstindeki keramik ve altın diademleriyle MÖ 325-275 yıllarına tarihlendirilmektedir. Karamattepe'de ortaya çıkarılan mezarların konteksti de, bu alanın Erken Hellenistik Dönem'den başlayarak MÖ 3. yüzyıl boyunca nekropolis olarak kullanıldığını göstermektedir (Tulunay 2015, 11, 14).

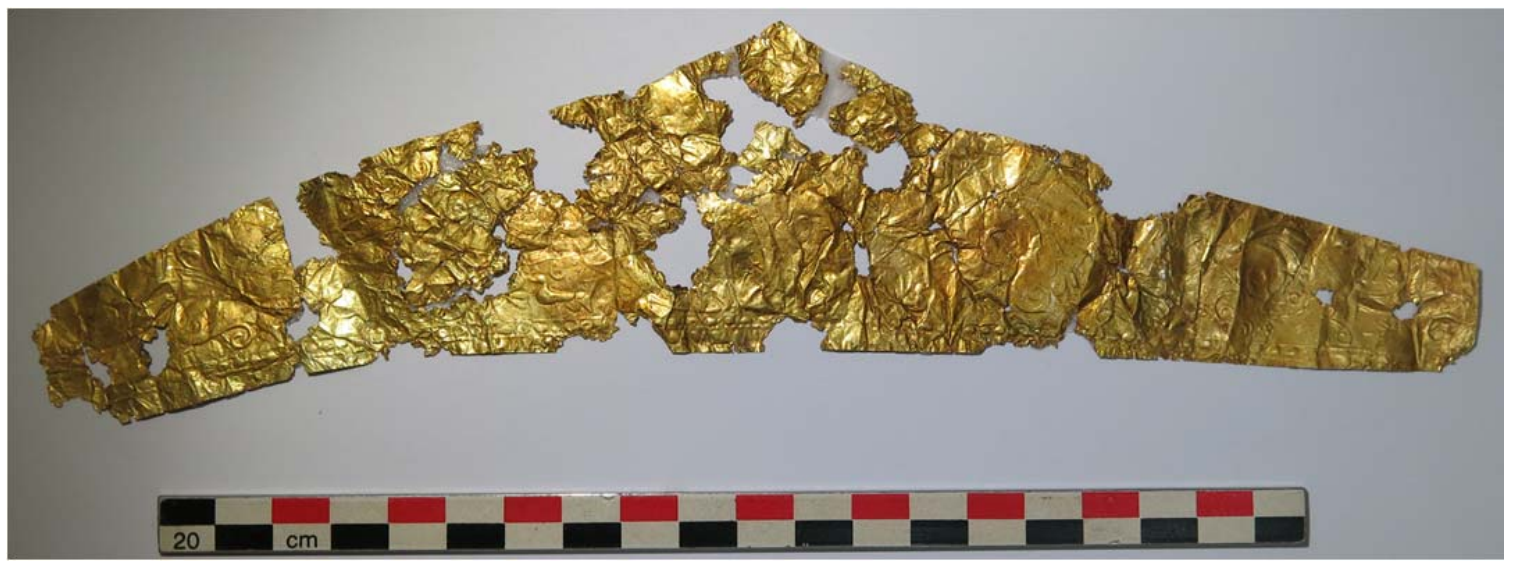

Fig. 7. Env. no. İzmir M. 852, Nif Dağı Kazısı M.08-50, yük. 5,7 cm, uz. 25,3 cm

\section{Yapım Tekniği}

Diademler, mezar hediyesi olarak ölünün başına takılarak kullanılmışlardır. Tüm olan iki diademin (İzmir Müzesi Env. No. 851 ve 852) uçlarında ölünün alnına bağlamak için ip delikleri görülmektedir. Mezar sahipleri muhtemelen başlarında diademler olduğu halde yakıldıktan sonra kalan kemik parçaları, küller ve diademler toplanarak kremasyon kabı olarak kullanılan amphoranın içine yerleştirilmiştir. Bu nedenle diademler şekilleri bozularak parçalandığ 1 ve üzerlerinde katlama izleri oluştuğundan bezemeleri takip etmek zorlaşmaktadır. Bezeme ögesi olarak bitkisel motifler kullanılmıştır. Sarmallar ve spiraller oluşturan kıvrımlı dalların uçlarında yapraklar, tomurcuklar bazen çiçekler ve aralarında kuşlardan oluşan bir kompozisyon yer alır. 852 ve 853 Env. No.lu diademlerin ortasında bir akanthus yaprağı ve 852 Env. No.lu diademde akanthus yaprağının iki yanında konmuş duran birer kuş görülmektedir. Alt kenar boyunca İon 
kymationu ve üzerindeki boncuk dizisi izlenmektedir. Alınlıklı altın şerit diademler, repoussé (kalıba çakma) yöntemi (Higgins 1961, 9-10; Williams \& Ogden 1994, 17-19; Bingöl 1999, 27; Treister 2001, xii-xviii, 176-181; Akyay-Meriçboyu 2001, 28, 32; Köroğlu 2004, 9-10) uygulanarak yapılmıştır. Diademlerin bezeme kompozisyonlarındaki benzerlik aynı kalıpların kullanıldığını göstermektedir. Altın levha, kalıba basılarak yüzeyine bezemeler oluşturulmuş, daha sonra kenarları kesilerek düzeltilmiş̧ir. Diademlerin kenarlarında kesim hataları nedeniyle bazen alt kenardaki bezemede bazen de sarmal dallarda kesinti görülmektedir.

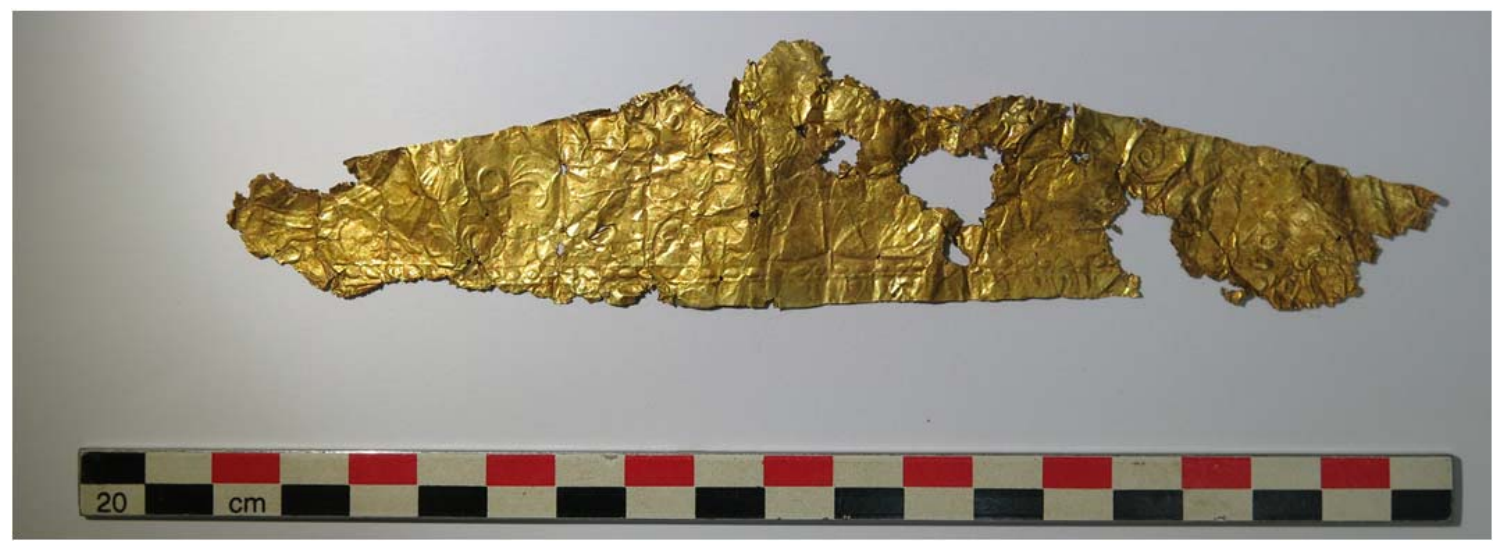

Fig. 8. Env. no. İzmir M. 853, Nif Dağı Kazısı M.08-51, yük. 4,3 cm, uz. 17,5 cm

\section{Benzerleri}

Karamattepe'de bulunan diademlerin hem biçim hem de bezeme yönünden yakın benzerleri İzmir İli Aliağa İlçesi'ndeki Kyme kazılarında bulunmuştur. Kyme nekropolisinde yapılan çalışmalarda ortaya çıkarılan diademler bugün İzmir Arkeoloji Müzesi'nde sergilenmektedir (Scatozza Höricht 2010, 108; La Marca 2012, 198, 200, 205 res. 10; Çırak \& Kaya 2011, 218, 220, 227 res. 5; Korkmaz \& Gürman 2012, 71, 75; Atıcı \& Karakaş 2014, 233, 237). Kyme'de bulunduğu söylenen ve British Museum'a (Env. No. 1877,0910.60) satılan yaklaşık 11 parça diadem (Williams \& Ogden 1994, 92-93; Scatozza Höricht 2010, 108-109) üzerinde de benzer sarmal dal bezemeleri görülmektedir. Louvre Müzesi'ndeki Smyrna kökenli olduğu bildirilen bir başka diadem parçası da hem aynı bölgeden oluşu hem de bezemelerinin özellikle de ortadaki akanthus yaprağının benzerliği açısından önemlidir (Louvre Müzesi Env. No. Bj 98; Coche de la Ferté 1956, 61, lev. xviii.2; Scatozza Höricht 2010, 112). Daha kuzeyde Troas bölgesinde Dardanos Tümülüsü (Çanakkale Müzesi Env. No. 2334h./1-7.1-7, 2334a, 2335b; Sevinç \& Treister 2003, 220-223, 234-235, lev. 1), Ilgardere (Çanakkale Müzesi; Körpe 2001, 231-235; Körpe 2004, 141-144), Madytos (New York Metropolitan Müzesi Env. No. 06.1217.1; Williams \& Ogden 1994, 108-109; The Madytos Jewelry 2006) ve Abydos yakınındaki Tagara'da (Victoria and Albert Museum Env. No. 627-1884) bulunan diademler de sarmal dal bezemeleriyle Karamattepe'dekilere yakındır. Öte yandan bu örneklerin çoğunda bitkisel bezemelerin yanı sıra figürler de yer almaktadır. Datça'da bulunan ve İstanbul Arkeoloji Müzeleri'nde korunan diadem (Akyay-Meriçboyu 2001, 184, res. 1) salt bitkisel bezemeleriyle Karamattepe ve Dardanos Tümülüsü örneklerine daha yakındır. Söz konusu örnekler için verilen tarihlendirmeler de Karamattepe diademleriyle uyumludur. 


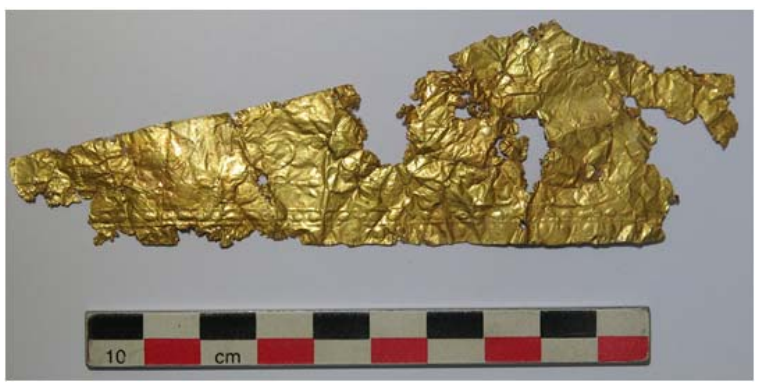

Fig. 9. Env. no. İzmir M. 854, Nif Dağı Nif M.08-52, yük. $4,3 \mathrm{~cm}$, uz. $12,5 \mathrm{~cm}$

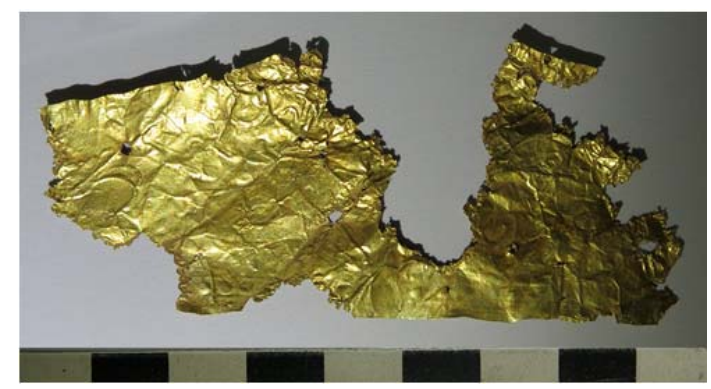

Fig. 10. Env. no. İzmir M. 855, Nif Dağı Kazısı M.08-83, yük. 3,7 cm, uz. 7,6 cm

\section{Sonuç}

Hellenistik Dönem'de nekropolis olarak kullanılan Karamattepe'nin ait olduğu yerleşimin yeri ve niteliği hakkında henüz yeterli bilgimiz yoktur. Fakat Karamattepe'nin, hemen yakınında, kuzeybatısındaki tepe üzerinde yer alan Ballıcaoluk ile yakın bağlantısı buluntularla kanıtlanmıştır. Bu bölgedeki baskın Pers etkisini kontrol etmek için emekli askerlere arazi verilerek Makedon kolonileri kurulduğu bilinmektedir. Epigrafik kaynaklar, burada katoikoi varlığını bildirmektedir (Cohen 1991, 41-50; Fingerson 1998, 107-120; Labarre 2004, 227-228), fakat bu yerleşimlerin askeri niteliğine ilişkin kuşkular vardır. Köy karakterindeki bazı yerleşimler de bu isimle anılmış olabilir (Şahin 1998; Akalın 2006, 72). Konumu nedeniyle Ballıcaoluk'taki yerleşim Hellenistik Dönem'de bir katoikia olabilir (Türkmen 2011, 264-265, 267; Türkmen Peker 2015, 24). Hem Ballıcaoluk hem de Karamattepe'de yapılan kazılarda bulunan Makedon sikkelerinin yoğunluğu da buna işaret eder (Lenger 2013a, 5; Lenger 2013b, 377-378). Ayrıca, kremasyon mezarların Hellenistik Dönem'de Makedonia'da yaygın oluşu (Sevinç \& Treister 2003, 252 dn. 315) Karamattepe KM 6'nın sahiplerinin Makedon kökenli olabileceğini akla getirmektedir.

\section{Yazarın Notu}

2008 Yı1ı Nif Dağı Kazısı buluntusu diademleri yayınlamam için izin veren kazı başkanı değerli Hocam Prof. Dr. Elif Tül Tulunay'a (İstanbul Üniversitesi) teşekkür ederim. Bu makalenin konusunu oluşturan diademlerle ilgili sözlü bir bildiri 9-11 Ekim 2015 tarihlerinde Salihli, Manisa'da düzenlenen Lidya 'Altın Ülke' Uluslararası Katılımlı Altın, Gemoloji ve Kuyumculuk Sempozyumu'nda sunulmuştur. Aynı sempozyuma Nif Dă̆ı Kazısı Kuyumculuk Verileri başlıklı bildiriyle katılan ve bulgularını benimle paylaşan meslektaşım Sayın Doç. Dr. Daniş Baykan'a (Trakya Üniversitesi) ve yine aynı sempozyumda Nif Dă̆ Kazısı Altın Diademlerinin Onarımı'nı sunan, diademlerin onarımını sabırla gerçekleştiren Onarım-Koruma Uzmanı Sayın Öğr. Gör. Ceren Baykan’a (M. A., Trakya Üniversitesi) teşekkürlerimi sunarım.

\section{KAYNAKÇA}

Akalın A. (2006). "Hellenleştirmede Bir Yerleşim Ögesi: Katoikia". Ankara Üniversitesi Dil ve TarihCoğrafya Fakültesi Tarih Bölümü Tarih Araştırmaları Dergisi 25/39 (2006) 65-74.

Akyay-Meriçboyu Y. (2001). Antikçağ'da Anadolu Takıları. İstanbul 2001.

Atıcı M. \& Karakaş G. (2014). "Kyme Doğu Nekropolü (İzmir İli, Aliağa İlçesi, Samurlu Köyü, 877 ve 879 Parsel)". 22. Müze Çalı̧̧maları ve Kurtarma Kazıları Sempozyumu, 14-17 Kasım 2013, Adana (2014) 229-242.

Bilgin M. (2015). "Pottery Finds from Nif-Olympus". Eds. E. Laflı \& S. Patac1. Recent Studies on the 
Archaeology of Anatolia: British Archaeological Reports International Series 2750 (2015) 27-40. Oxford.

Bingöl I. (1999). Anadolu Medeniyetleri Müzesi Antik Takılar. Ankara 1999.

Coche de la Ferté É. (1956). Les Bijoux Antiques. Paris 1956.

Cohen G. M. (1991). "Katoikia, Katoikoi and Macedonians in Asia Minor". Ancient Society 22 (1991) 41-50.

Çırak N. \& Kaya S. (2011). "2009 İDÇ Nekropolü Kurtarma Kazısı”. 19. Müze Çalışmaları ve Kurtarma Kazılarl Sempozyumu, 29 Nisan-1 Mayls 2010, Ordu (2011) 217-232.

Fingerson K. R. (1998). Smyrna 573: A Study in Hellenistic Civic Organization During the Third Syrian War (246-241 B.C.). Yayımlanmamış Doktora Tezi. Wisconsin-Madison Üniversitesi, Ann Arbor 1998.

Higgins R. A. (1961). Greek and Roman Jewellery. Londra 1961.

Korkmaz E. \& Gürman B. (2012). "İzmir İli, Aliağa İlçesi, Bozköy Biçerova Mevkii Kyme Antik Kenti Doğusu Sur Dışı Yapıları ve Doğu Nekropolü Kurtarma Kazısı”. 20. Müze Çalışmaları ve Kurtarma Kazıları Sempozyumu, 25-29 Nisan 2011, Bodrum (2012) 69-93.

Köroğlu G. (2004). Anadolu Uygarlıklarında Takı. İstanbul 2004.

Körpe R. (2001). “Ilgardere Diademi”. 12. Müze Çalışmaları ve Kurtarma Kazıları Sempozyumu, 25-27 Nisan 2001, Kuşadasl (2001) 231-236.

Körpe R. (2004). “A New Gold Diadem from Ilgardere”. Studia Troica 14 (2004) 141-145.

La Marca A. (2012). “Kyme 2010: Şehir ve Yayılım Alanı, Yeni Topoğrafik Verileri”. AST XXVII (2012) 191-208.

Labarre G. (2004). "Phrourarques et phrouroi des cités grecques d'Asie Mineure à l'époque hellénistique”. Eds. J. C. Couvenhes \& H. L. Fernoux. Les cités grecques et la guerre en Asie Mineure à l'époque hellénistique (2004) 221-248. Tours.

Lenger D. S. (2013a). “Yeni Bulgular Işı̆̆ında Kaunos'a Atfedilen Makedon Krali Darpları”. Adalya XVI (2013) 1-9.

Lenger D. S. (2013b). "Salamis'e Atfedilen Makedon Krali Bronzlar Üzerine Bir Değerlendirme”. Olba XXI (2013) 371-386.

“The Madytos Jewelry, Hellenistic Greek; Said to be from Madytos”. (2006, Ekim). Kaynak: http://www.metmuseum.org/toah/works-of-art/06.1217.1-.13.

Scatozza Höricht L. A. (2010). "Kyme di Eolide e l'oro di Dioniso: Nuovo diadema dalla necropoli". Archäologischer Anzeiger 20101 (2010) 105-123.

Sevinç N. \& Treister M. (2003). "Metalwork from the Dardanos Tumulus”. Studia Troica 13 (2003) 215260.

Şahin I. (1998). Lydia'da Küçük Yerleşimler. Yayımlanmamış Doktora Tezi. Ege Üniversitesi, İzmir 1998.

Treister M. Y. (2001). Hammering Techniques in Greek and Roman Jewellery and Toreutics. Leiden 2001.

Tulunay E. T. (2010). "Nif (Olympos) Dağı Araştırma ve Kazı Projesi: 2008 Yı1ı Kazısı”. KST XXXI/2 (2009) 387-408.

Tulunay E. T. (2015). "Nif-Olympus Survey and Excavation Project Between 2004 and 2010”. Eds. E. Laflı \& S. Patac1. Recent Studies on the Archaeology of Anatolia: British Archaeological Reports International Series 2750 (2015) 11-18. Oxford.

Türkmen M. (2011). “İzmir Nif Dağı Ballıcaoluk Yerleşimine İlişkin Gözlemler”. Colloquium Anatolicum 10 (2011) 261-275.

Türkmen Peker M. (2015). "A Site in the Territory of Nif-Olympus: Ballıcaoluk”. Eds. E. Laflı \& S. Patac1. Recent Studies on the Archaeology of Anatolia: British Archaeological Reports International Series 2750 (2015) 19-25. Oxford.

Williams D. \& Ogden J. (1994). Greek Gold: Jewellery of the Classical World. Londra 1994. 